\title{
Biological monitoring of occupational exposure to tetrahydrofuran
}

\author{
C N Ong, S E Chia, W H Phoon, K T Tan
}

\begin{abstract}
Occupational exposure to tetrahydrofuran (THF) was studied by analysis of environmental air, blood, alveolar air, and urine from 58 workers in a video tape manufacturing plant. Head space gas chromatography (GC) with an FID detector was used for determination of THF concentration in alveolar air, urine, and blood. Environmental exposure to THF was measured by personal sampling with a carbon felt passive dosimeter. When the end of shift urinary THF concentrations were compared with environmental time weighted average (TWA) values, urinary THF concentration corrected for specific gravity correlated well with THF concentration in air $(r=0.88)$, and uncorrected urinary THF concentration gave a similar result $(r=0.86)$. Correction for creatinine in urine weakened the correlation ( $r$ $=0.56)$. For exposure at the TWA concentration of $200 \mathrm{ppm}$ the extrapolated concentration of THF was $33 \mu \mathrm{mol} / 1$ in blood and $111.9 \mu \mathrm{mol} / 1$ (61 $\mu \mathrm{mol} / \mathrm{g}$ creatinine) or $109 \mu \mathrm{mol} / 1$ at a specific gravity of 1.018 in urine. The correlation between exposure to THF and its concentration in exhaled breath and blood was low $(r=0.61$ and 0.68 respectively). Laboratory methodological considerations together with the good correlation between urinary THF concentration and the environmental concentration suggest that THF concentration in urine is a useful biological indicator of occupational exposure to THF.
\end{abstract}

Tetrahydrofuran (THF) is a colourless organic solvent belonging to a group of cyclic ethers. It dissolves readily in water and most organic solvents. It can also dissolve many types of plastic materials-

Department of Community, Occupational, and Family Medicine, National University of Singapore, Singapore 0511

C N Ong, S E Chia

Department of Industrial Health, Ministry of Labour, Singapore

W H Phoon, K T Tan for example, polyvinyl chloride, polyurethanes, and epoxy compounds. Its application is increasing rapidly and it has uses in glues, paints, varnishes, inks, and dispersing agents in textile processing. In recent years THF has been used extensively in an iron oxide coating agent employed in production of audio and video tapes.

This volatile solvent has a boiling point of $66^{\circ} \mathrm{C}$ with a vapour pressure of $176 \mathrm{~mm} \mathrm{Hg}$; therefore high vapour concentrations may develop at the workplace. It is believed to have a low toxicity compared with other cyclic ethers. ${ }^{1}$ Nevertheless, mild effects on the central nervous system are not uncommon among workers exposed to THF. ${ }^{2}$ The current threshold limit value (TLV) of THF is $200 \mathrm{ppm}^{3}$

On contact with air, THF may form peroxides, which increase its irritating effect. Irritation of the skin and mucous membranes has been described recently in exposed workers. ${ }^{4}$ Tetrahydrofuran might have contributed to the development of status epilepticus on awakening from enfluran anaesthesia in a worker occupationally exposed to the solvent. Liver enzyme activities were raised in persons exposed to THF itself or together with other potentially hepatotoxic solvents. ${ }^{45}$ More recently, Garnier et al reported that THF was responsible for some effects on the central nervous system and the irritation of mucous membranes in their patients exposed to high concentrations of THF. ${ }^{6}$ In animal studies, an alteration of tracheal ciliary activity was seen at a concentration of $100 \mathrm{ppm}$. Oral administration of THF produced haemorrhagic and ulcerative gastritis. $^{7}$

Our present study is an extension of two earlier investigations on the environmental and biological monitoring of workers engaged in the manufacture of video and audio tapes. ${ }^{89}$ The objectives were: (1) to see if it is possible to carry out biological monitoring of workers exposed to this solvent by measuring THF concentrations in the alveolar air, blood, and urine and (2) to evaluate these three common biological monitoring methods under field conditions.

\section{Materials and methods}

SUBJECTS

Fifty eight male workers from a video tape manufacturing plant in Singapore participated. Their ages 
ranged between 21 and 48 years and their average working experience was $7 \cdot 2$ years. The average exposure concentration of THF was in the range 2 to $150 \mathrm{ppm}$. Basically, the production process involves the coating of iron oxide on to polythene film and THF is one of the main solvents used. Preliminary environmental monitoring indicated that in the coating department the concentration of THF varied throughout the workshift, occasionally reaching $200 \mathrm{ppm}$. Workers in the calendering and packaging departments were generally exposed to steady concentrations of THF. The average concentrations in the two sections were about 36 and 10 ppm respectively. The other solvents used were methyl isobutyl ketone, toluene, and cyclohexanone. Ten of the workers were moderate smokers (below 10 cigarettes daily) and four were heavy smokers. Workers with known heart, lung, liver, kidney, or any other chronic diseases were excluded.

Both environmental and biological monitoring were carried out at midweek. Eight hospital staff without occupational history of exposure to solvents provided standard samples.

\section{ANALYSIS OF EXHALED BREATH}

Samples of breath were obtained from each worker immediately after his workshift. To minimise the possibility of contamination, samplings were carried out in a clean area in the administrative building where the mean concentration of THF in air did not exceed $100 \mathrm{ppb}$. Sampling was usually performed five to 10 minutes after exposure to avoid the very fast washout of THF from the lungs that occurs in the first 10 minutes after leaving the workplace.

The subject was asked to breathe as normally as possible, and then to expire through a sampling tube open at both ends. Just before the expiration finished, the tube was closed at both ends and $300 \mathrm{ml}$ exhaled air was retained. The collection tubes were equipped with perforated screw caps, each containing a rubber disc and a teflon membrane through which a small volume of air $(100 \mu \mathrm{l})$ could be taken by syringe for analysis by gas chromatography. The tube was conditioned before use by heating to $80^{\circ} \mathrm{C}$ and flushing repeatedly with clean air. Blank tubes were handled in the same way as the sample tubes. The detection limit using this method was $40 \mathrm{ppb}$.

This technique of sampling had previously been found to give satisfactory results in our laboratory. Sample loss by tube desorption or by the dissolution of THF in breath condensate was insignificant. Analysis was conducted within two hours of returning to the laboratory.

\section{DETERMINATION OF THF CONCENTRATION IN BLOOD}

Blood samples were collected from workers at the end of their workshift. To minimise the possibility of contamination, blood was collected in the adminis- trative building of the factory at the end of the workshift. Heparin was the anticoagulant. One $\mathrm{ml}$ of venous blood was collected for each worker and kept in a $2 \mathrm{ml}$ vial with a screw cap and a teflon membrane. The glass vials were kept at $5^{\circ} \mathrm{C}$ during the journey from the factory to the laboratory and then incubated at $60^{\circ} \mathrm{C}$ for 30 minutes before analysis. For the analysis, $200 \mu \mathrm{l}$ of the air from the headspace was injected with a heated gas tight syringe into the gas chromatograph.

The concentration of THF was measured in blood samples using a gas chromatograph equipped with a $530 \mu \mathrm{m}$ silicone gum capillary column.

Standard samples were obtained by adding known amounts of THF to glass vials that contained $1 \mathrm{ml}$ of blood sample from unexposed persons. The standard samples were kept in the oven at $60^{\circ} \mathrm{C}$ for 30 minutes before testing.

The accuracy of the method was assessed by spiking blood samples and also by the internal standard method (in the present study methyl ethylketone (MEK) was used). The calibration graph was linear for absolute amounts of THF in the range 2$40 \mu \mathrm{mol} / \mathrm{l}$. The within run precision of the method was obtained by processing four aliquots of spiked blood samples with THF at concentrations ranging from 5 to $100 \mu \mathrm{mol} / 1$. The day to day variation was calculated from spiked samples assayed on four consecutive days. The detection limit was expressed as peak height relative to the base line level. Using the above conditions, blood THF at a concentration of $0.25 \mu \mathrm{mol} / 1$ could be detected.

THF was found in the blood of the eight unexposed hospital staff. Although no significant loss of THF from the blood was noted for samples stored for more than one week, all determinations of THF concentration in blood were carried out within two days after collection.

\section{DETERMINATION OF THF CONCENTRATION IN URINE}

Urine samples were collected in polycarbonate bottles at the end of the workshift and stored at $-20^{\circ} \mathrm{C}$. The samples were collected in the adjacent administrative building within 30 minutes of leaving the factory floor. Analysis was performed the next day. This was carried out by transferring $1 \mathrm{ml}$ urine samples into $5 \mathrm{ml}$ gas chromatography vials with screw caps. The vials were incubated at $75^{\circ} \mathrm{C}$ for 30 minutes and $200 \mu \mathrm{l}$ of the headspace air was used for the gas chromatographic determination of THF concentration.

The detection limit of the urinary THF method was $20 \mu \mathrm{mol} / 1$ and THF was not detected in control urine samples from the eight non-exposed subjects.

The results were presented as observed $(\mu \mathrm{mol} / \mathrm{l})$ or after correction for creatinine concentration $(\mu \mathrm{mol} / \mathrm{g}$ creatinine) or for specific gravity at $1 \cdot 018 .^{10}$ The specific gravity was measured by refractometry and 
Table 1 Conditions for gas chromatography

\begin{tabular}{ll}
\hline GC model & Hewlet Packard 5890A \\
Detector & $\begin{array}{l}\text { Flame ionisation detector (FID) } \\
\text { Shtegrator }\end{array}$ \\
Column & $\begin{array}{l}10 \mathrm{~m} \times 530 \mu \mathrm{m} \text { internal diameter } \\
2.65 \mu \mathrm{m} \text { film thickness HP-1 } \\
\text { Methyl silicone gum capillary } \\
\text { column }\end{array}$ \\
& \\
$\begin{array}{l}\text { Temperature: } \\
\text { Injector }\end{array}$ & $100^{\circ} \mathrm{C}$ \\
$\begin{array}{l}\text { Detector } \\
\text { Column; }\end{array}$ & $200^{\circ} \mathrm{C}$ \\
$\quad \begin{array}{l}\text { for environmental } \\
\text { samples }\end{array}$ & $35^{\circ} \mathrm{C} \times 1.5 \mathrm{~min} ; 25^{\circ} \mathrm{C} / \mathrm{min} ; 80^{\circ} \mathrm{C}$ \\
Column; & $\times 1.5 \mathrm{~min}$ \\
$\quad$ for biological & $35^{\circ} \mathrm{C} \times 1.5 \mathrm{~min} ; 25^{\circ} \mathrm{C} / \mathrm{min} ;$ \\
$\quad$ samples & $80^{\circ} \mathrm{C} \times 0.5 \mathrm{~min} ; 70^{\circ} \mathrm{C} / \mathrm{min} ;$ \\
\hline
\end{tabular}

the creatinine by an Abbott autoanalyser based on Jaffe's method.

\section{ENVIRONMENTAL AIR SAMPLES}

Individual exposure to THF at the workplace was monitored with a $3 \mathrm{M}$ organic vapour monitor throughout the whole workshift of eight hours. The passive dosimeters were attached to the collar or shirt pocket of the workers before they entered the plant. Dosimeters were detached at the end of shift and stored at $-4^{\circ} \mathrm{C}$ until analysis. Determination of the THF concentration in the dosimeter was carried out within one week. An autosampler was used together with an integrator for the gas chromatographic determination of THF concentration. The injection volume was $2 \mu \mathrm{l}$.

\section{GAS CHROMATOGRAPHY CONDITIONS}

Table 1 gives the gas chromatography conditions for analysis of biological and environmental samples. Internal quality control was carried out with the urine and blood samples obtained from hospital staff who were not occupationally exposed to organic solvents. The within run coefficient of variation $(\mathrm{CV})$ for urinary THF concentration was $6.2 \%$ and the day to day $\mathrm{CV}$ was $8.3 \%$. The detection limit was $2 \mu \mathrm{mol} /$ 1. The CVs for blood THF concentrations were $3.3 \%$ and $8.8 \%$ within run and day to day respectively. Figure 1 shows typical chromatograms of THF in blood and urine. The peak of THF appeared at about 1.2 minutes after injection, with no interference from other blood or urine components.

\section{STATISTICAL ANALYSIS}

Statistical analysis was performed with the PC statistical analysis system (SAS) package on an IBM compatible personal computer. PROC REG was used for linear regression analysis.

\section{Results}

Table 2 summarises the data for environmental
THF concentrations and the various biological measurements.

Figure 2 shows the correlation between blood THF and environmental THF concentrations. The linear correlation coefficient was $r=0.68$ $(\mathrm{p}<0.001)$. The slope of the regression line (the ratio between blood THF and environmental THF concentrations) was $0 \cdot 15$.

Figure 3 shows the relation between environmental THF and breath THF concentrations. The correlation coefficient was poorer than that between blood and environmental THF concentrations $(r=0.61)$. The slope of the regression line (the ratio between exhaled air and environmental THF concentration) was 0.03 .

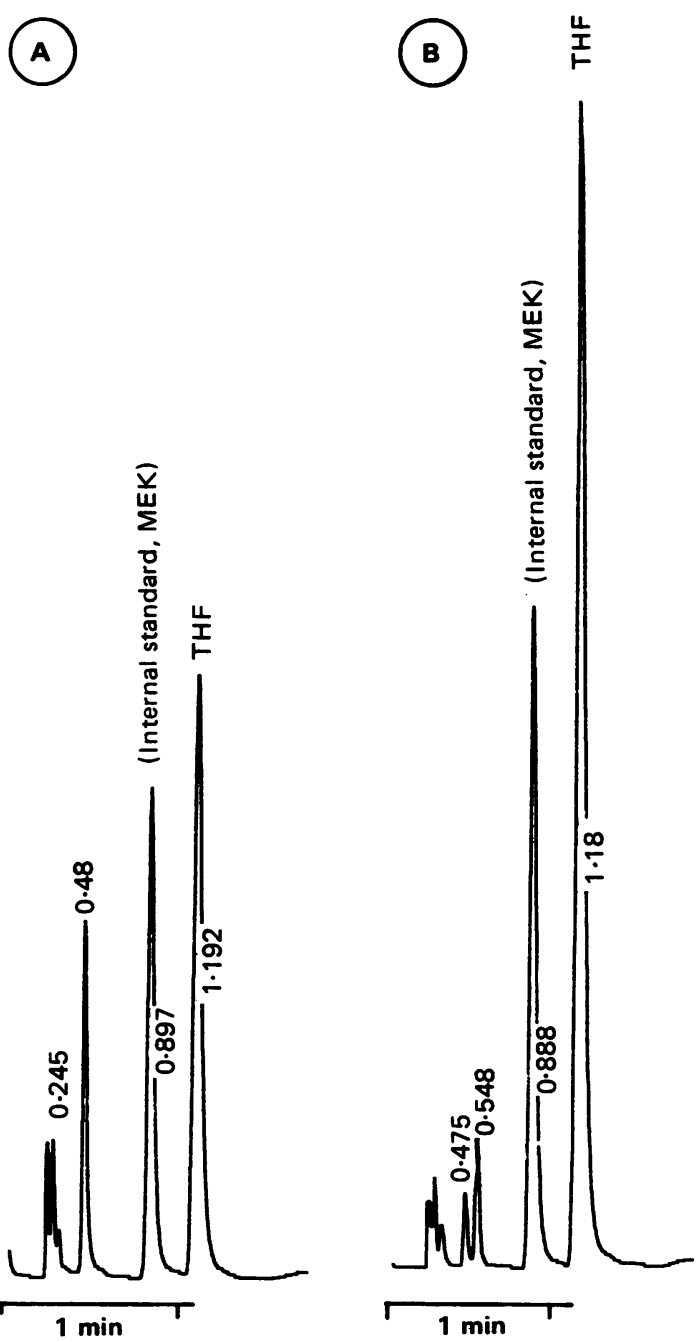

Figure 1 Headspace gas chromatographic determination of tetrahydrofuran in $A$, blood; $B$ urine of a $T H F$ worker. 
Table 2 Mean concentrations and ranges of various parameters measured

\begin{tabular}{|c|c|c|c|}
\hline Parameter measured & $\begin{array}{l}\text { No of } \\
\text { samples }\end{array}$ & Mean (SD) & Range \\
\hline \multirow{3}{*}{$\begin{array}{l}\text { Concentration of: } \\
\text { Environmental THF } \\
\text { (ppm) } \\
\text { Breath THF }(\mathrm{ppm}) \\
\text { Blood THF }(\mu \mathrm{mol} / 1) \\
\text { Urinary THF }(\mu \mathrm{mol} / 1) \\
\text { Urinary THF }_{\alpha}(\mu \mathrm{mol} / 1) \\
\text { Urinary THF }_{\mathrm{cre}}(\mu \mathrm{mol} / \mathrm{g} \\
\text { creatinine) }\end{array}$} & & & \\
\hline & $\begin{array}{l}58 \\
58 \\
48 \\
58 \\
54\end{array}$ & $\begin{array}{rr}24.7 & (35.0) \\
1.8 & (3.8) \\
6.3 & (6.6) \\
17.3 & (20.4) \\
16.7 & (19.8)\end{array}$ & $\begin{array}{l}0 \cdot 2-143 \cdot 0 \\
0-27 \cdot 3 \\
0 \cdot 3-25 \cdot 6 \\
2-89 \cdot 6 \\
2-89.5\end{array}$ \\
\hline & 58 & $13.3(17 \cdot 8)$ & $2-97.4$ \\
\hline
\end{tabular}

sg = Adjusted for specific gravity.

cre $=$ Adjusted for creatinine concentration

Figures $4 \mathrm{~A}, 4 \mathrm{~B}$, and $4 \mathrm{C}$ show the correlations between urinary THF and environmental THF concentrations. The correlation coefficients were $0.86,0.88$, and 0.50 , for uncorrected urine samples,

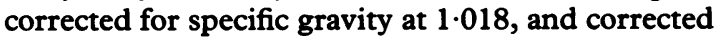
for creatinine respectively. Correction for specific gravity only improved the correlation coefficient slightly.

Table 3 summarises the relation between THF concentrations in exhaled air and blood and urinary THF concentrations measured at the end of the workshift. The THF concentration in breath correlated poorly with blood and urine, whereas blood THF concentration had a good association with urinary THF concentration (uncorrected and corrected for specific gravity) with $r=0.78$. Again correction for creatinine concentrations weakened correlations.

\section{Discussion}

CONCENTRATION OF THF IN EXHALED BREATH

Analysis of exhaled breath is becoming increasingly popular as a method of biological monitoring. The technique has recently been given prominence by its incorporation into biological exposure indices of the

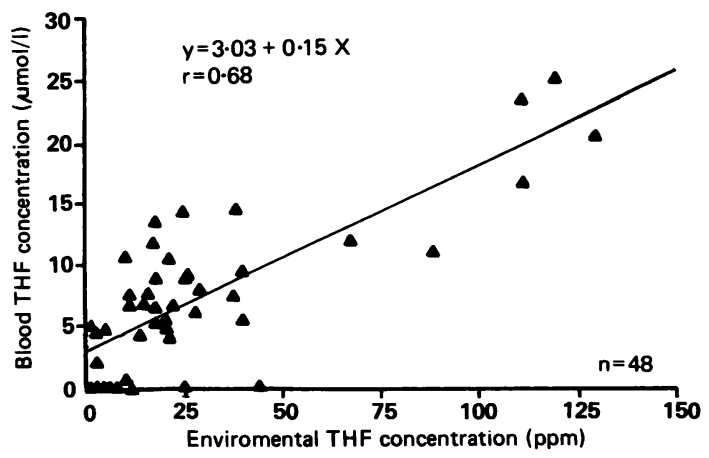

Figure 2 Relation between THF concentration in blood and breathing zone air. Points are individual values.

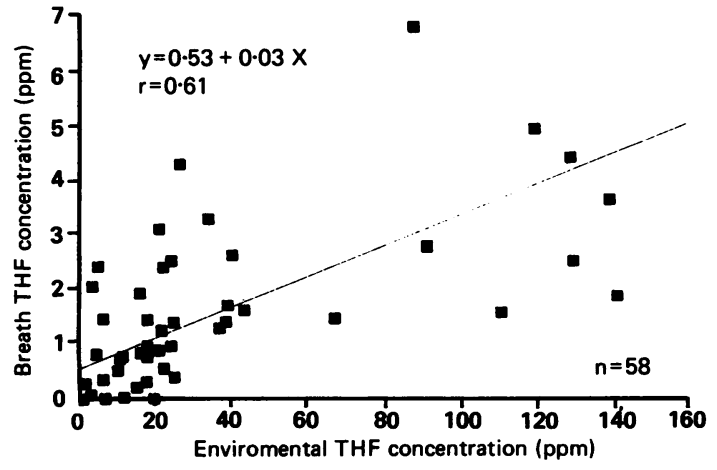

Figure 3 Relation between THF concentration in exhaled breath and breathing zone air.

threshold limit values. ${ }^{3}$ Although much work has been undertaken on breath analysis as a technique of biological monitoring under controlled conditions in exposure chambers, few data are available from field studies.

Analysis of exhaled breath is non-invasive and it is thus more acceptable to workers than collecting blood. By measuring exhaled breath at the end of exposure, it is theoretically possible to estimate the amount of material present in the body. ${ }^{11}$ Breath analysis is, however, complex. One of the major setbacks is that the results can vary considerably depending on the type of sampling technique and time of sampling. ${ }^{12}$ Breath analysis will reflect the uptake accurately provided that exposure is relatively constant over the work period, but in field situations the exposure usually varies throughout the day. Teramoto et al have recently shown that with deep respiration under heavy work load the pulmonary absorption of THF was $70 \%$ compared with $60 \%$ for normal breathing. ${ }^{13}$ Several other factors may also affect breath analysis-namely, the solubility of the solvent, metabolic clearance, cigarette smoking, absorption from other routes, vital capacity of the lung, and physical work load. ${ }^{11}{ }^{12}$

One major disadvantage of breath analysis is that samples have to be analysed soon after collection as storage leads to significant loss, ${ }^{912}$ and this technique has been found to be unsatisfactory in various studies. ${ }^{14} 15$

Data from our present study show that the concentration of THF in breath is proportional to the THF concentration in breathing zone air between 10 to $100 \mathrm{ppm}$. The scatter plot, however, shows large individual variation (fig 3 ), although to avoid differences in post-exposure loss exhaled air was collected within 10 minutes of the end of the workshift. Until more reliable monitoring devices are available, breath analysis does not appear to be a useful biological monitoring method for establishing the degree of exposure to THF. 

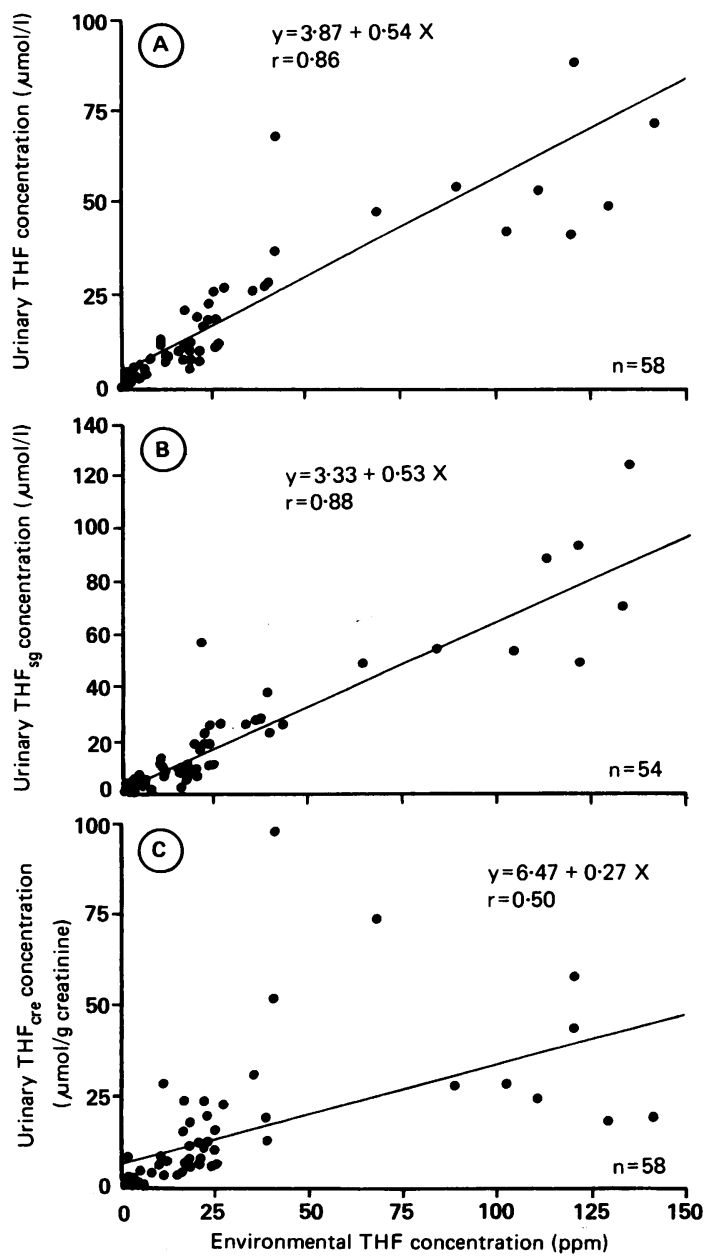

Figure 4 , relation between urinary $T H F$ concentration (unadjusted) and breathing zone air. $B$, relation between urinary THF concentration (adjusted for specific gravity of 1.018 ) and breathing zone air. $C$, relation between urinary THF concentration ( $\mu$ mol/g creatinine) and breathing zone air.

\section{CONCENTRATION OF THF IN BLOOD}

The results show a linear relation between blood THF concentration and environmental exposure to THF $(r=0.68)$. The technique is reliable and sensitive enough to measure an exposure concentration of $10 \mathrm{ppm}$ THF. As THF is not present in the unexposed population, measurement of THF concentration in blood can be used for biological monitoring of exposure.

Nevertheless, it is important to mention that if skin absorption is significant, venous blood is not a reliable indicator of uptake by inhalation. Aitio et $a l^{16}$ have shown that results were unreliable when venous blood was used for monitoring workers in whom skin absorption was significant. In this factory no form of respiratory protective device was worn and skin contact with THF among some of the operators was extensive. No work clothes were worn and several operators wore singlets at work. Also this method is not useful for routine monitoring, as collection of blood is usually not welcomed by the workers.

In our present study, the average environmental exposure was $25 \mathrm{ppm}$ and none of the workers had an exposure concentration above $150 \mathrm{ppm}$. Calculations based on an exposure of $25 \mathrm{ppm}$ would be expected to produce a blood concentration of $6.7 \mu \mathrm{mol} / 1$ at the end of shift. Linear extrapolation for exposure at a TWA of $200 \mathrm{ppm}^{3}$ gives a value of $33 \mu \mathrm{mol} / 1 \mathrm{THF}$ in blood.

\section{CONCENTRATION OF THF IN URINE}

Urinary THF concentration (uncorrected and corrected for specific gravity) correlated well with environmental exposure to THF. Urinary THF concentration also correlated well with THF concentration in blood (table 3). From the laboratory point of view, analysis for urinary THF concentration is easy and rapid. Furthermore, THF is not usually present in the urine and thus it is a reliable index of exposure.

Corrections for urinary creatinine concentration weaken the correlations with exposure. This finding is in agreement with the experience of Ghittori et al ${ }^{17}$ obtained with the biological monitoring of nine different organic solvents. It is believed that adjustment for creatinine excretion is suitable for chemicals excreted by glomerular filtration but it is not relevant for agents such as nitrous oxide, methanol, and some other organic solvents that are excreted by tubular diffusion. ${ }^{18}$

The method used in the present investigation for determination of THF concentration in urine is simple, specific, and sensitive. It does not require pretreatment of the sample before analysis, and unlike exhaled air, the samples do not require to be

Table 3 Correlations between environmental, breath, blood, and urinary THF concentrations

\begin{tabular}{|c|c|c|c|c|c|c|}
\hline \multirow[b]{2}{*}{$\begin{array}{l}\text { Environmental THF } \\
\text { Breath THF } \\
\text { Blood THF }\end{array}$} & Breath THF & Blood THF & Urinary $T H F$ & Urinary $T H F_{*}$ & \multicolumn{2}{|c|}{ Urinary $T H F_{\text {cre }}$} \\
\hline & $0.61 \quad(58)$ & $\begin{array}{ll}0.68 & (48) \\
0.48 & (48)\end{array}$ & $\begin{array}{ll}0.86 & (58) \\
0.64 & (58) \\
0.65 & (48)\end{array}$ & $\begin{array}{ll}0.88 & (54) \\
0.64 & (54) \\
0.78 & (44)\end{array}$ & $\begin{array}{l}0.50 \\
0.47 \\
0 \cdot 39\end{array}$ & $\begin{array}{l}(58) \\
(58) \\
(48)\end{array}$ \\
\hline
\end{tabular}

No of samples in parentheses. 
analysed on the same day. Furthermore, urine samples deteriorate slower than blood specimens. ${ }^{18}$ Also, THF is normally not present in the urine of unexposed persons, and thus it is suitable for monitoring of exposure. One further advantage of directly measuring the parental compound is that measurement of metabolites in urine is less specific due to influence of diet, exposure to other organic solvents, and other factors. ${ }^{19}$ Moreover, urine analysis is non-invasive and thus is suitable for routine screening. Good correlation between urine concentrations and environmental exposure makes measuring the concentration of THF in urine the most appropriate method.

In an earlier study, Imbriani $e t a^{20}$ showed a good correlation between 1,1,1-trichloroethane concentration in urine and environmental exposure. Similar observations have been recorded for other organic solvents-namely, methanol, ${ }^{21}$ methyl ethyl ketone, ${ }^{22}$ styrene, ${ }^{23}$ and acetone. ${ }^{24}$ These studies, together with the present investigation of THF, suggest that measurement of solvents in urine is a suitable biological monitoring method.

At an exposure of $200 \mathrm{ppm}$, the corresponding. calculated concentration for urinary THF was $111.9 \mu \mathrm{mol} / 1,109 \mu \mathrm{mol} / 1$ adjusted for specific gravity at 1.018 , and $60.5 \mu \mathrm{mol} / \mathrm{g}$ creatinine for urine corrected for creatinine concentration.

No attempt was made to estimate the urinary biological half life of THF as it was not possible to follow up urinary excretion in detail after the end of the workshift. A simple follow up study on eight of the workers, however, showed that THF was not detected in the urine collected the next morning (15 hours post-exposure). This suggests that either the excretion of THF is rapid or it is converted to other compound(s).

In summary, our results suggest that measurement of THF concentration in urine is sensitive and specific for monitoring of exposure, whereas exhaled breath and blood analyses appear to be less suitable. The data also show that unmetabolised THF in urine correlates better with environmental exposure than THF in blood or exhaled breath. Laboratory methodological considerations are also in favour of determining urinary THF as it is non-invasive and, unlike the analysis of exhaled air, the sample does not require to be analysed on the day of collection.

This work was supported in part by the Singapore Turf Club Grant No 5712. We thank G L Sia and H Y Ong for their technical assistance.

Requests for reprints to: C N Ong, Department of Community, Occupational, and Family Medicine, National University of Singapore, Singapore 0511.
1 Browning E. Toxicology and metabolism of industrial solvents. Amsterdam: Elsevier, 1965:700-1.

2 Elovaara E, Pfaffli P, Savolainen H. Burden and biochemical effects of extended tetrahydrofuran vapour inhalation of three concentration levels. Acta Pharmacologica et Toxicologica 1984;54:221-6.

3 American Conference of Governmental Industrial Hygienists. Threshold limit values and biological exposure indices for 1990. Cincinnati, Ohio: ACGIH, 1990.

4 Juntunen J, Kaste M, Harkonen $H$. Cerebral convulsion after enfluran anaesthesia and occupational exposure to tetrahydrofuran. J Neurol Neurosurg Psychiatry 1984;47:1258-9.

5 Edling $C$. Interaction between drugs and solvents as a cause of fatty change in the liver. $B r J$ Ind Med 1982;39:198-9.

6 Garnier R, Rosenberg N, Puissant JM, et al. Tetrahydrofuran poisoning after occupational exposure. $\mathrm{Br} J$ Ind Med 1990;46:677-8.

7 Ikeoka H, Ohashi Y, Maruoka K, et al. Effects of tetrahydrofuran exposure on the ciliary activity and morphology of tracheal epithelium in rabbits. Osaka City Med J 1984;30:53-68.

8 Ong CN, Sia GL, Chia SE, Phoon WH, Tan KT. Determination of cyclohexanol in the urine and its use in environmental monitoring of cyclohexanone exposure. J Anal Tox 1991; 15:13-6.

9 Sia GL, Ong CN, Chia SE, Phoon WH, Tan KT. Biological and environmental monitoring of methyl ethyl ketone. Environmental Monitoring and Assessment (in press).

10 Ong CN, Lee BL, Foo SC. Specific gravity adjustment for urinary analysis of aminolevulinic acid. Am Ind Hyg Assoc J 1985;46:10-11.

11 Droz PO, Gillemin MP. Occupational exposure using breath analysis. J Occup Med 1986;28:593-602.

12 Campebell L, Marsh DM, Wilson HK. Towards a biological monitoring stragegy for toluene. Ann Occup Hyg 1987;31: 121-33.

13 Teramoto $\mathrm{K}$, Horiguchi S, Kageyama $\mathrm{M}$, et al. Expiratory elimination of tetrahydrofuran by humans. Journal of the Science of Labour 1988;64:54-7.

14 Money CD, Gray CN. Exhaled breath analysis as a measure of workplace exposure to benzene. Ann Occup Hyg 1989;33: 257-62.

15 Perbellini L, Faccini GB, Passini F, et al. Environmental and occupational exposure to benzene by analysis of breath and blood. Br J Ind Med 1988;45:345-52.

16 Aitio A, Pekari K, Jarnisalo J. Skin absorption as a source of error in biological monitoring. Scan J Work Environ Health 1984; 10:317-20.

17 Ghittori S, Imbrani E, Pezzagno G, Capodaglio E. The urinary concentration of solvents as a biological indicator of exposure: Proposal for the biological equivalent exposure limit for nine solvents. Am Ind Hyg Assoc J 1987;48:786-90.

18 Rosenberg J, Fiserova-Bergerrova V, Lowry LK. Biological monitoring IV. Measurements in urine. Appl Ind Hyg 1989;4: 16-20.

19 Bernard A, Lauwerys R. Biological monitoring of exposure to industrial chemicals. In: Waldron HA, ed. Occupational health practice. 3rd ed. London: Butterworths, 1988:203-16.

20 Imbriani M, Ghittori S, Pezzagno G, et al. 1,1,1-Trichloroethane in urine as biological index of exposure. Am J Ind Med 1988;13:211-22.

21 Sedivec V, Mraz M, Flek J. Biological monitoring of persons exposed to methanol vapours. Int Arch Occup Environ Health 1981;48:257-67.

22 Miyasaka M, Kumai M, Koizumi A, et al. Biological monitoring of occupational exposure to methyl ethyl ketone by means of urinalysis of methyl ketone itself. Int Arch Occup Environ Health 1982;50:131-7.

23 Pezzagno G, Ghittori S, Imbriani M, et al. Urinary elimination of styrene in experimental and occupational exposure. Scan $J$ Work Environ Health 1985;11:371-9.

24 Pezzagno G, Imbriani M, Ghittori S, et al. Urinary elimination of acetone in experimental and occupational exposure. Scan J Work Environ Health 1986;12:603-8.

Accepted 14 January 1991 